\title{
Targeting of miR-432 to myozenin1 to regulate myoblast proliferation and differentiation
}

\author{
R.M. Ren ${ }^{1,2 *}$, H. Liu ${ }^{1,2 *}$, S.H. Zhao ${ }^{1,2,3}$ and J.H. Cao ${ }^{1,2,3}$ \\ ${ }^{1}$ Key Laboratory of Agricultural Animal Genetics, Breeding, \\ and Reproduction of the Ministry of Education, Wuhan, Hubei, China \\ ${ }^{2}$ Key Laboratory of Swine Genetics and Breeding of the Ministry of Agriculture, \\ Huazhong Agricultural University, Wuhan, Hubei, China \\ ${ }^{3}$ The Cooperative Innovation Center for Sustainable Pig Production, Wuhan, \\ Hubei, China \\ *These authors contributed equally to this study. \\ Corresponding author: J.H. Cao \\ E-mail: jhcao@mail.hzau.edu.cn
}

Genet. Mol. Res. 15 (4): gmr15049313

Received September 20, 2016

Accepted November 17, 2016

Published December 19, 2016

DOI http://dx.doi.org/10.4238/gmr15049313

Copyright (C 2016 The Authors. This is an open-access article distributed under the terms of the Creative Commons Attribution ShareAlike (CC BY-SA) 4.0 License.

ABSTRACT. MicroRNAs (miRNAs) play important roles in the
development and biochemical functions of skeletal muscles. However,
targeting of miRNAs to structural genes involved in Z-discs have
not been investigated. Here, we describe a highly expressed miRNA,
miR-432, in pig embryonic skeletal muscle, which appeared to target
myozenin1 (MYOZ1), a protein involved in the muscular sarcomere
microstructure. Our results showed that miR-432 is involved in
muscle development in the developing pig. In addition, it promoted
differentiation of the C2C12 myoblast cell line into myotubes. We also
demonstrated that inhibition of miR-432 reduced proliferation of $2 \mathrm{C} 12$ 
cells, suggesting that miR-432 is involved in regulation of myoblast proliferation. Moreover, molecular markers of muscle differentiation and fiber type (Myh7/ slow and Myh4/ fast IIB) showed that miR-432 reduced the differentiation rate of $\mathrm{C} 2 \mathrm{C} 12$ cells. These results provide insights into the potential functions of miR-432 as well as its proposed target, MYOZ1, during muscle development. This may lead to applications for further improvements in porcine muscle growth, and may enhance our understanding of complex inherited human muscle disorders.

Key words: Muscle differentiation; MiR-432; MYOZ1

\section{INTRODUCTION}

Muscle growth and development are central in determining pig carcass and muscle weights. The process of muscle growth and development is referred to as myogenesis. Currently, a number of studies are investigating the molecular basis for its regulation; however, the identification of key regulatory gene networks involved in myogenesis remains a major challenge (Tabebordbar et al., 2013; Tran et al., 2013; Yu and Zuo, 2013). Noncoding RNAs, specifically microRNAs (miRNAs), are now being considered as possible players in the regulation of gene networks, including those associated with muscle growth and development. miRNAs, a family of highly conserved non-coding RNAs approximately 22 nucleotides in length, regulate gene expression at the post-transcriptional level (Flowers et al., 2013; Ying et al., 2013). miRNAs are involved in muscle-regulatory networks and can regulate the expression of key transcription factors and signaling mediators in muscle development and function (Siengdee et al., 2013). Skeletal muscle cells arise from embryonic mesoderm during development. Multiple regulatory factors, including transcription factors and cellular signaling molecules, play critical roles in the control of muscle cell proliferation and differentiation. Previous studies have shown that the muscle specifically expresses, or is highly enriched in, certain miRNAs. For example, miR-1, miR-133, miR-206, and miR208 regulate transcriptional networks that include serum response factor, myocyte enhancer factor-2, and myocardin and thereby regulate myoblast proliferation and differentiation during myogenesis (Bostjancic et al., 2010; Belevych et al., 2011; Lee et al., 2013). Indeed, aberrant miRNA expression has been observed in certain muscle diseases, including cardiac and skeletal muscle hypertrophy, heart failure, and muscular dystrophy (Siegismund et al., 2016).

The basic unit of a skeletal muscle, called a sarcomere, is composed of cross-linked microfilaments separated by Z-discs. Repeating sections of sarcomeres form highly ordered threedimensional structures and play important roles in the contraction and organization of skeletal muscles (Lin et al., 2014). In recent years, many Z-disc proteins have been identified (Cheng et al., 2010; Chen et al., 2015). Myozenin1 (MYOZ1) is an $\alpha$-actinin - and $\gamma$-filamin-binding Z-disc protein expressed predominantly in skeletal and cardiac muscles. It was shown to be highly expressed in early stage porcine embryos, and its expression was found to be gradually decreased in adult pigs (McDaneld et al., 2009). It has been suggested that MYOZ1 family members may contribute to the formation and maintenance of Z-discs and may also be involved in cell signaling via binding to calcineurin (Wang et al., 2006; Arola et al., 2007). Furthermore, MYOZ1 may be involved in remodeling and maintenance of type-II fibers via NuRF1 and NuRF2 regulation (Moriscot et al., 2010). MYOZ1 and MYOZ3 are highly expressed in fast twitch muscle fibers,

Genetics and Molecular Research 15 (4): gmr15049313 
whereas MYOZ2 is highly expressed in cardiac muscle slow twitch fibers (von Nandelstadh et al., 2009). However, it is not clear whether miRNAs can regulate MYOZ proteins in skeletal muscles. In the present study, we identified a highly expressed miRNA, miR-432, in porcine embryonic skeletal muscles, which appeared to target the muscular sarcomere microstructure protein MYOZ1. Previous studies have suggested that miR-432 is involved in cell proliferation, as changes in its expression have been observed in several cancer studies. D'Angelo et al. (2012) reported that expression of miR-432 was down-regulated in GH adenomas (somatotrophic adenomas) in the pituitary. In addition, miR-432 expression in postoperative hepatocellular carcinoma patients was higher than that in patients with an earlier tumor recurrence (Huang et al., 2012). miR-432 has also been proposed as a potential blood biomarker for schizophrenia diagnosis (Lai et al., 2011). Most studies to date have focused on the relationship between miR-432 and disease states; however, the exact role of miR-432 under physiological conditions remains unclear.

The present study therefore aimed to examine the biological effects of miR-432 and its proposed target, MYOZ1, in pig muscle development as well as during myoblast cell proliferation and differentiation. Our results indicated that miR-432 and MYOZ1 have regulatory functions in muscle cell proliferation and differentiation.

\section{MATERIAL AND METHODS}

\section{Tissues and plasmids}

This study was conducted in accordance with the university regulations on animal care and use committee. Three independent Landrace pig embryos were collected at 33 (E33) and 65 days of gestation (E65). The longissimus muscles were separated using ophthalmic forceps under a stereo microscope. In addition, the longissimus muscles from three adult (180 days old) Landrace pigs were sampled at the location of the last rib. Tissue samples were rapidly frozen in liquid nitrogen and stored at $-80^{\circ} \mathrm{C}$ until further use. The 3'UTR of the MYOZ1 gene was cloned into the psiCHECK2 duo-luciferase vector (Promega, USA) through the XhoI and NotI restriction sites (Renilla-3'UTR) in the duo-luciferase assay system (Promega). In order to overexpress MYOZ1, the full length MYOZ1 gene including the 3'UTR was cloned into the pcDNA3.1+ vector (Life Technologies, Thermo Fisher Scientific, USA) using XhoI and HindIII restriction sites. The N-terminus of the MYOZ1 coding sequence was tagged via a flag epitope (MYOZ1Tag). Restriction enzymes and first strand cDNA synthesis kits were from purchased from Fermentas (Shenzhen, China). All other reagents used were of analytical grade.

\section{Cell culture and transfection}

Fetal bovine serum (FBS), donor horse serum, Dulbecco's modified Eagle's medium (DMEM), and cell culture related solutions were all obtained from Hyclone Technologies, Inc. (Beijing, China). Mouse-derived myoblast C2C12 cells were cultured in DMEM supplemented with $10 \%$ FBS. Cell differentiation was induced in DMEM supplemented with $2 \%$ horse serum. At approximately $80 \%$ confluence, cells on 6-well plates were transfected with $0.25 \mu \mathrm{g}$ Renilla-3'UTR, MYOZ1Tag constructs, or miR-432 duplex mimics (GenePharma, Shanghai, China) using the Lipofectamine 2000 reagent (Invitrogen, USA), according to manufacturer instructions. Porcine kidney (PK)-15 cells and baby hamster kidney (BHK) cells were cultured in DMEM supplemented with 10\% FBS.

Genetics and Molecular Research 15 (4): gmr15049313 


\section{Quantitative real-time PCR (qPCR)}

Total RNA was isolated from porcine skeletal muscles as well as $\mathrm{C} 2 \mathrm{C} 12$, PK-15, and BHK cells using TRIzol reagent (Invitrogen). cDNA was synthesized from $1 \mu \mathrm{g}$ total RNA, using the ReverTra Ace transcription kit (TOYOBO, Osaka, Japan) according to the manufacturer protocols. For individual qPCRs, the SYBR green I master kit (Roche, USA) was used to assess relative expression of miR-432 and MYOZ1, and the assays were performed on a Roche LightCycler 480 machine. U6 small nuclear RNA, 18S RNA, and $\beta$-tubulin were used as internal controls for miR-432 (U6) and MYOZ1 (18S and $\beta$-tubulin). Relative mRNA expression was quantified by the delta-delta-CT method.

\section{miRDuo-luciferase activity analysis}

miRDuo-luciferase assays were initiated by seeding $5 \times 10^{5}$ PK-15 cells per well onto 6-well plates. Cells were then transfected with $0.25 \mu \mathrm{g}$ Renilla-3'UTR construct and $0.75 \mu \mathrm{g}$ miRNA duplex mimics (miR-432, its inhibitor, or negative control). Following an overnight culture, transfected cells were passively lysed, and duo-luciferase activities were measured using the Duo-luciferase assay kit (Promega) and the VICTOR X2 multilabel plate reader (PerkinElmer, USA). The relative ratios of Renilla and Firefly luciferase activities were calculated to determine transfection efficiencies. Decreases in this relative ratio indicated binding of miR-432 to the $3 \notin \mathrm{UTR}$ of MYOZ1 present in the construct.

\section{Immunofluorescence (IF)}

PK-15 cells were cultured overnight on 24-well plates after being transfected with the MYOZ1Tag constructs and duplex miRNA mimics. Cells in each well were fixed for $15 \mathrm{~min}$ in $4 \%$ formaldehyde, and were washed twice with PBS at room temperature $\left(25^{\circ} \mathrm{C}\right)$. Cell membrane was permeabilized with $10 \%$ FBS and $0.1 \%$ Triton X-100 in PBS for $1 \mathrm{~h}$. The monoclonal primary MYOZ1 antibody (Sigma-Aldrich, USA) was added at 1:200 dilution, and was incubated with 1\% FBS in PBS at $4^{\circ} \mathrm{C}$ overnight with continual mixing/shaking. This was followed by incubation with the FITC-labeled secondary antibody (1:1000 dilution, Santa Cruz Biotechnology, USA) at room temperature for $1 \mathrm{~h}$. Nuclear staining was carried out with DAPI for 2 min. Fluorescent images were collected using an ECLIPSE TE2000-S microscope (Nikon, USA).

\section{Western blot analysis}

PK-15 cells transfected with the MYOZ1Tag constructs (with or without miR-432 duplex mimics) were lysed in $50 \mathrm{mM}$ Tris- $\mathrm{HCl}, 0.5 \% \mathrm{SDS}, 20 \mathrm{mg} / \mathrm{mL}$ leupeptin, $10 \mathrm{mg} / \mathrm{mL}$ phenylmethylsulfonyl fluoride, $1 \mathrm{mM}$ sodium orthovanadate, $10 \mathrm{mM}$ sodium pyrophosphate, $10 \mathrm{mM}$ sodium fluoride, and $1 \mathrm{mM}$ dithiothreitol. The cell lysates were loaded onto $12 \%$ SDSpolyacrylamide gradient gels and electro-transferred to nitrocellulose immuno-blot PVDF membranes (Bio-Rad, CA, USA). The membranes were incubated in blocking buffer $(5 \%$ skimmed milk in PBS) for $2 \mathrm{~h}$. Primary MYOZ1 antibody (1:500 dilution) in $1 \mathrm{X}$ TBS and $0.1 \%$ Tween- 20 was added overnight at $4{ }^{\circ} \mathrm{C}$ with gentle shaking. This was followed by $2 \mathrm{~h}$ incubation with corresponding 1:1000 horseradish peroxidase (HRP)-conjugated secondary antibody (CST, USA). Supersensitive luminescent reactions (Pierce, USA) catalyzed by HRP were detected on ImageQuant LAS 4000 mini (GE, USA). $\beta$-tubulin was used as loading control.

Genetics and Molecular Research 15 (4): gmr15049313 


\section{Enzyme-linked immunosorbent assay (ELISA)}

Flag-tagged MYOZ1 (MYOZ1Tag) expression in PK-15 cells was detected using a monoclonal rabbit anti-flag primary antibody (CST) at $0.5 \mu \mathrm{g} / \mathrm{mL}$ and goat anti-rabbit secondary antibodies coupled with HRP (CST) at $0.8 \mu \mathrm{g} / \mathrm{mL}$. Cells were washed 5 times with PBS, and chemiluminescence was detected and quantified using the Super-signal ELISA substrate (Pierce) and the VICTOR X2 multilabel plate reader (PerkinElmer).

\section{Real-time monitoring of cell proliferation}

$\mathrm{C} 2 \mathrm{C} 12$ cells were seeded at $3 \times 10^{3}$ cells per well on 16-well E-plates (Roche). Proliferating $\mathrm{C} 2 \mathrm{C} 12$ cells were transfected with either the miR-432 inhibitor or the negative control mimics. The cell index was monitored on the xCELLigence RTCA DP instrument (Roche) over $64 \mathrm{~h}$, which included a 16-h period for cell adhesion followed by a 48 -h period of cell proliferation. The sampling intervals were every $80 \mathrm{~min}$ during cell adhesion and every 60 min during proliferation.

\section{Statistical analysis}

All statistical analyses were performed using the GraphPad Prism 5 software (GraphPad, USA). Comparisons between the two treatment groups at each time point were analyzed separately using a grouped Student $t$-test. Unless otherwise noted, error bars represent SE for the three independent replicates.

\section{RESULTS}

\section{Expression patterns of miR-432 and MYOZ1 mRNA in porcine skeletal muscle}

Interestingly, expression pattern of porcine miR-432 in skeletal muscles was opposite to that of MYOZ1 from the embryonic to adult stages during development. Expression of MYOZ1 was found to increase over 100 times in adult muscles (ADU) compared with that in embryonic day-33 (E33) muscles (Figure 1A). However, a 10-fold reduction in miR-432 expression was found from E33 to adult stages (Figure 1B). These results suggest that miR432 may be a potential regulator of MYOZ1 expression pattern in pig skeletal muscles.

\section{Quantification of miR-432and MYOZ1 in myogenic and non-myogenic cells}

Cell-based quantification of miR-432 and MYOZ1 was conducted in three different cell lines - mouse $\mathrm{C} 2 \mathrm{C} 12$ myoblast cells, PK-15 cells, and BHK cells. The results showed that miR-432 was highly expressed in proliferating myogenic $\mathrm{C} 2 \mathrm{C} 12$ cells compared with that in the other two non-myogenic cell lines (Figure 2A). Moreover, miR-432 expression was highest in proliferating $\mathrm{C} 2 \mathrm{C} 12$ cells (D0), and its expression was 100-fold higher than cells at 2, 4, and 6 days of differentiation (D2, D4, and D6) (Figure 2B). In agreement with previously observed expression patterns in developing porcine skeletal muscles, expression of MYOZ1 was opposite to that of miR-432. Lowest MYOZ1 expression was observed in cells at D0 and D2, but increased with differentiation (D4 and D6); a 4-fold increase was observed at D6 (Figure 2C). 
A

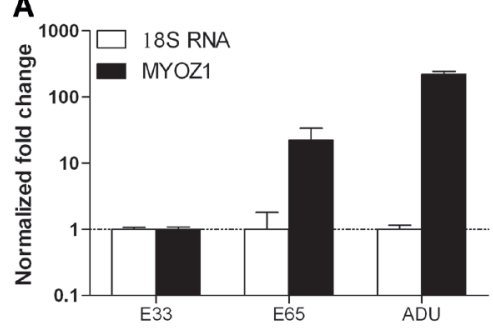

B

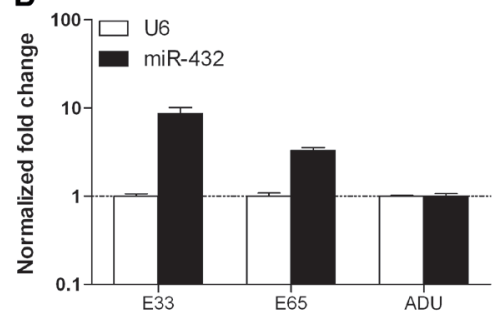

Figure 1. Quantification of MYOZ1 mRNA (A) and miR-432 (B) at different developmental time points in porcine skeletal muscles. Three time points were sampled: embryonic day 33 (E33), embryonic day 65 (E65), and adult stage (ADU). MYOZ1 mRNA and miR-432 expression profiles of three Landrace pigs were quantified at each time point.

A

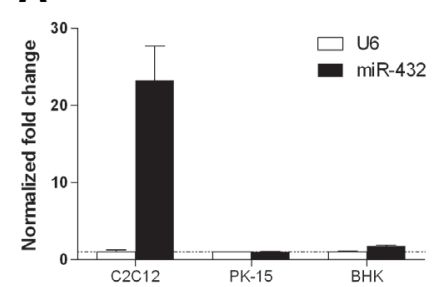

B

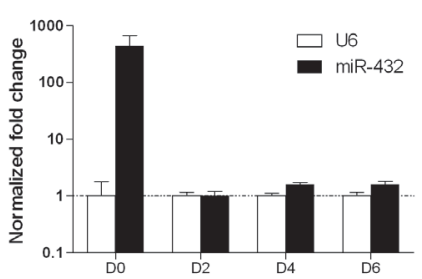

C

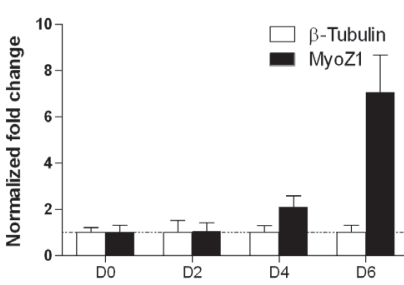

Figure 2. Quantification of miR-432 and MYOZ1 mRNA in cells. A. Expression of miR-432 in myogenic $\mathrm{C} 2 \mathrm{C} 12$ cells, non-myogenic PK-15 cells, and BHK cells. B. Expression of miR-432 in C2C12 cells at days 0, 2, 4, and 6 of differentiation. C. MYOZ1mRNA expression in $\mathrm{C} 2 \mathrm{C} 12$ cells at days $0,2,4$, and 4, and 6 days of differentiation.

\section{miR-432 targeting of MYOZ1}

In order to investigate whether MYOZ1 is a target of miR-432, duo-luciferase reporter assays were conducted in PK-15 cells transfected with the Renilla-3'UTR vector. Renilla luminescence was significantly reduced by miR-432 mimics compared to that in the negative control (NC) (Figure 3A). Moreover, PK-15 cells transfected with the flag-tagged MYOZ1 vector (MYOZ1Tag) showed increased flag epitope, as determined by ELISA (Figure 3B), but this was reduced by miR-432 mimics. Cells transfected with a flag-tagged GFP construct were used as positive controls (PC), and tag-free MYOZ1+3'UTR vectors were used as NCs. As expected, Mock-transfected PK-15 cells showed very low levels of endogenous MYOZ1 protein, as demonstrated by western blot results (Figure 3C). However, cells transfected with the tag-free MYOZ1+3'UTR vector showed increased MYOZ1 protein expression, which was reduced when co-transfected with miR-432 (Figure 3C). Together, these results further suggest that miR-432 targets MYOZ1 by binding to its 3'UTR region.

\section{IF detection of miR-432 targeting MYOZ1}

Further cellular evidence of miR-432 targeting MYOZ1 was obtained from an IF assay where PK-15 cells were transiently co-transfected overnight with MYOZ1Tag vector and miR-432 mimics. Based on FITC fluorescent intensity, results showed that the MYOZ1 protein was significantly decreased in cells co-transfected with miR-432 mimics compared to that in the negative control (Figure 4). However, no difference in cell density was detected, as 
demonstrated by nuclear DAPI staining, suggesting that neither MYOZ1 nor miR-432 had any effect on proliferation of PK-15 cells.
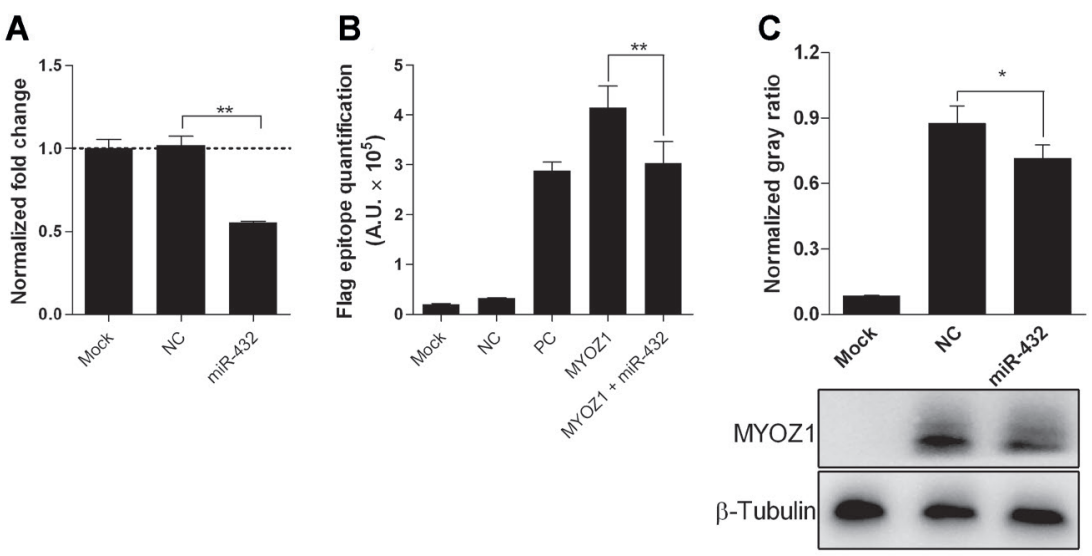

Figure 3. miR-432 inhibits expression of MYOZ1 by targeting its 3'UTR. Expression of MYOZ1 when miR-432 was co-transfected with the luciferase MYOZ1-3'UTR vector in PK-15 cells was detected via the duo-luciferase assay system (A), an ELISA assay for the MYOZ1 Flag epitope (B) and western blot for the MYOZ1 protein (C).

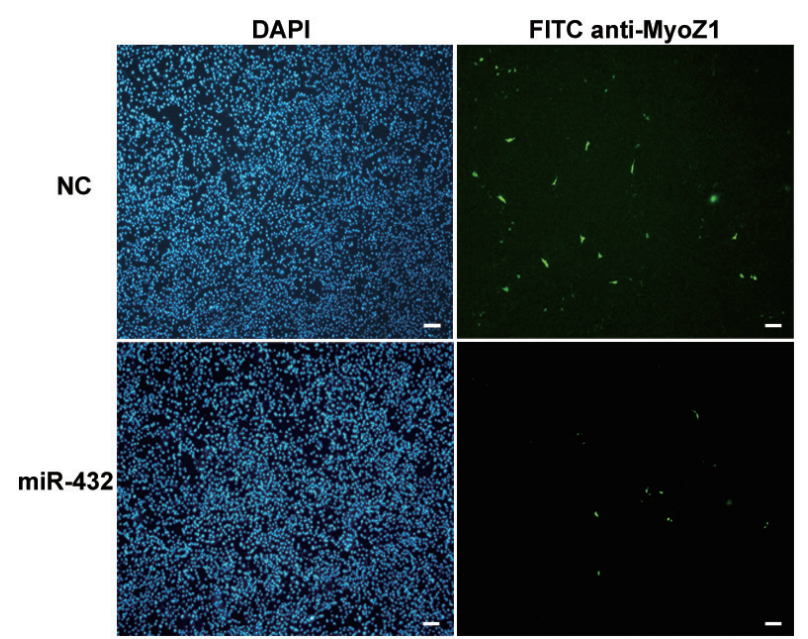

Figure 4. miR-432 reduces MYOZ1 protein expression. PK-15 cells were transiently co-transfected overnight with the MYOZ1Tag vector in the presence (miR-432) or absence (NC) of miR-432 mimics. Fluorescent images were captured at $340 \mathrm{~nm}$ for nuclear DAPI staining (left) and $488 \mathrm{~nm}$ for anti-MYOZ1 FITC staining (right). The scale bar indicates $50 \mu \mathrm{m}$.

\section{Proliferation blocked by miR-432 in myogenic C2C12 cells}

MiR-432 and MYOZ1 were highly expressed in porcine skeletal muscle and myogenic $\mathrm{C} 2 \mathrm{C} 12$ cells, which suggested that miR-432 targeting of MYOZ1 may be specific to myogenic 
cells. As higher expression of miR-432 was found in proliferating $\mathrm{C} 2 \mathrm{C} 12$ cells, it was possible that miR-432 inhibitor mimics may inhibit proliferation of $\mathrm{C} 2 \mathrm{C} 12$ cells. Thus, $\mathrm{xCelligence}$ real-time monitoring was conducted on $\mathrm{C} 2 \mathrm{C} 12$ cells transfected with miR-432 inhibitor mimics. We found that miR-432 inhibitor mimics significantly reduced proliferation of $\mathrm{C} 2 \mathrm{C} 12$ cells compared with NC mimics or mock transfected cells (Figure 5). No difference in cell proliferation was detected in the first 16-h period, during which cell adhesion was taking place. However, miR-432 inhibitor mimics clearly inhibited proliferation of $\mathrm{C} 2 \mathrm{C} 12$ cells, as indicated by the decreased cell index slope during the last $48 \mathrm{~h}$. Interestingly, all growth curves peaked at approximately $48 \mathrm{~h}$, possibly because the cells had reached maximum density and/ or the media had become depleted.

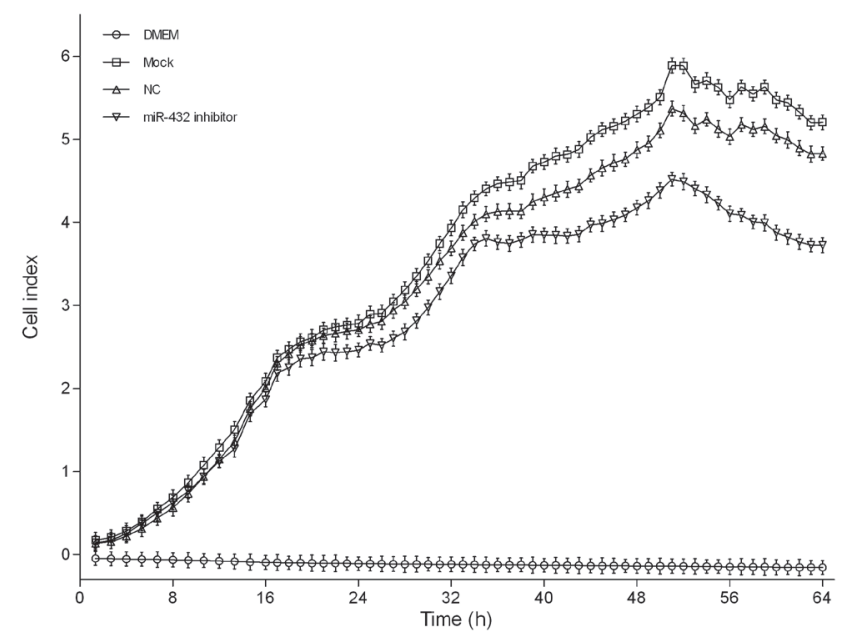

Figure 5. Proliferation of $\mathrm{C} 2 \mathrm{C} 12$ cells during miR-432 inhibitor transfection. Proliferating $\mathrm{C} 2 \mathrm{C} 12$ cells were monitored for $64 \mathrm{~h}$ in total, which was comprised of $16 \mathrm{~h}$ of cell adhesion and $48 \mathrm{~h}$ of cell proliferation. The sampling intervals were every 80 minutes during cell adhesion and every 60 min during proliferation.

\section{Slow twitch muscle fibers associated markers reduced by miR-432}

Skeletal muscle can generally be classified into two main types: slow twitch (also called type I) and fast twitch (type II) muscle fibers. The slow muscles are more efficient at using oxygen to generate ATP for continuous, extended muscle contractions. The $\mathrm{C} 2 \mathrm{C} 12$ cells terminally differentiate into fast and slow twitch myotubes, which is determined by fast (Myh4) and slow twitch muscle fiber (Myh7) marker genes. The results demonstrated that differentiation from myoblasts to myotubes in $\mathrm{C} 2 \mathrm{C} 12$ cells was associated with the quantity of Myh4 and Myh7. The forming rate of slow twitch muscle fibers was a time dependent process, whereas fast twitch muscle fibers demonstrated steady rates of formation (Figure 6A). However, miR-432 transfection resulted in remarkable disorganization in the formation of fast and slow twitch muscle fibers in differentiating C2C12 cells. This was characterized by a significant reduction in slow twitch muscle fiber formation based on quantification of Myh7 markers (Figure 6B). 
A

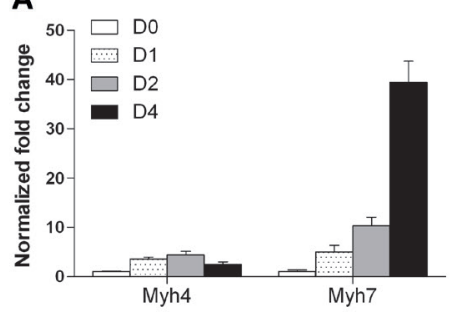

B

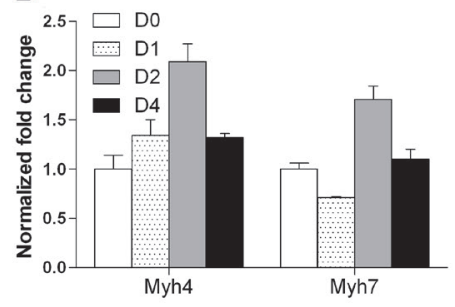

Figure 6. miR-432 transfected $\mathrm{C} 2 \mathrm{C} 12$ cells show reduced or delayed expression of differentiation/ fiber type markers. A. Expression of Myhr4 (type II/fast muscle fiber marker) and Myh7 (type I/slow muscle fiber) in controltransfected C2C12 cells. B. Expression of Myhr4 and Myhr7 in miR-432-transfected C2C12 cells.

\section{DISCUSSION}

The assembly of muscular sarcomeres in the embryonic stage is crucial for normal physiological functions of skeletal muscles. The Z-disc is a highly ordered structure at the border between two sarcomeres. Structural disorders of Z-discs are associated with muscular dysfunction (Cheng et al., 2010). Aberrant expression as well as knock-outs of Z-disc proteins leads to defective muscle Z-discs, resulting in abnormal structure and function of skeletal muscles (Lin et al., 2014; Chen et al., 2015). MYOZ1, as an associated member protein of skeletal muscles, may participate in the formation and structural stability of Z-discs.

miR-432, a skeletal muscle enriched miRNA, was first identified to target the Z-disc associated protein MYOZ1. Therefore, by understanding its functions, we will gain greater insights into muscular functions and pathological disorders. Of interest, miR-136 also binds to MYOZ1. However, as demonstrated by ELISA and western blot results, only miR-432, not miR-136, could reduce the expression of MYOZ1 at the translational level.

MYOZ1 is involved in fast and slow twitch fiber switching (Moriscot et al., 2010), which suggests that miR-432 may also be associated with muscle fiber composition in skeletal muscles. We first investigated the effect of miR-432 on myoblast proliferation in the $\mathrm{C} 2 \mathrm{C} 12$ cell line. Formation of the two types of muscle fibers were examined via expression level of marker genes. miR-432 promoted myoblast $\mathrm{C} 2 \mathrm{C} 12$ cells proliferation and blocked slow twitch muscle fiber formation. When miR-432 was overexpressed in differentiating $\mathrm{C} 2 \mathrm{C} 12$ cells, Myh7, the marker gene of slow twitch muscle fibers, was significantly reduced, suggesting that miR-432 promotes myoblast $\mathrm{C} 2 \mathrm{C} 12$ cells proliferation. Expression of the fast twitch muscle fiber marker gene Myh4 was similar to that of the control; it is possible that expression of Myh4 was too low to detect any changes. Therefore, the interaction mechanism between miR-432 and MYOZ1 needs to be further investigated.

Our results demonstrated that miR-432 and MYOZ1 have an inverse relationship during development in swine skeletal muscles. At early embryotic stages, high expression of miR-432 was detected, suggesting that it may contribute to skeletal muscle development. As the fetus develops into an adult, a reduction in skeletal muscle miR-432 was detected via qPCR. On the other hand, expression of MYOZ1 was found to increase with embryonic development, suggesting that miR-432 and MYOZ1 may interact to modulate muscle quality.

This study was the first to identify MYOZ1 as a target of miR-431, and that this interaction may participate in mammalian skeletal muscle development. Previous studies have demonstrated that interactions between MYOZ1 and MuRF1/MuRF2 are required for 
maintenance of type-II muscle fibers. MuRF1/MuRF2 KO mice exhibited loss of myozenin-1 expression in the tibialis anterior muscle, suggesting that MuRF1/MuRF2 act as regulators of the calcineurin/NFAT pathway. Therefore, MuRF1 and MuRF2 together are required for maintenance of type-II fibers, possibly via regulation of MYOZ (Moriscot et al., 2010). MYOZ1 knockout mice showed augmented exercise abilities as well as elevated slow muscle fiber type ratio in skeletal muscles (Frey et al., 2000). It was discovered that MYOZ1 could bind to Z-disc-associated proteins, which may affect skeletal muscle Z-disc assembly and stabilization. Since the discovery of the involvement of lin-4 miRNAs in gene expression regulation in Caenorhabditis elegans, miRNAs have become a target of research for posttranscriptional gene regulation.

In recent years, more attention has been placed on the relationship between meat quality/taste and carcass mass. The ability of miR-432 to regulate skeletal muscle fiber type and promote myoblast proliferation via targeting of MYOZ1 expounded a new way to modulate and control skeletal muscle conditions. Furthermore, interactions between miR432 and MYOZ1 may alter the composition of skeletal muscles, thereby inducing changes in functional performance that may affect appearance and taste of meats. While the exact mechanism of miR-432 and MYOZ1 is yet unknown, further investigation may provide clues to elucidate the relationship between miRNAs and skeletal muscles in swine.

\section{Conflicts of interest}

The authors declare no conflict of interest.

\section{ACKNOWLEDGMENTS}

Research supported by grants from the National Science and Technology Support Program (\#2015BAD03B01), the National Natural Science Foundation of China (\#31472074), the National High-tech R\&D Program of China (\#2013AA102502), and the Innovation Team of Molecular and Cellular Engineering of China (Guangdong) (\#2011A020102003).

\section{REFERENCES}

Arola AM, Sanchez X, Murphy RT, Hasle E, et al. (2007). Mutations in PDLIM3 and MYOZ1 encoding myocyte Z line proteins are infrequently found in idiopathic dilated cardiomyopathy. Mol. Genet. Metab. 90: 435-440. http://dx.doi. org/10.1016/j.ymgme.2006.12.008

Belevych AE, Sansom SE, Terentyeva R, Ho HT, et al. (2011). MicroRNA-1 and -133 increase arrhythmogenesis in heart failure by dissociating phosphatase activity from RyR2 complex. PLoS One 6: e28324. http://dx.doi.org/10.1371/ journal.pone. 0028324

Bostjancic E, Zidar N, Stajer D and Glavac D (2010). MicroRNAs miR-1, miR-133a, miR-133b and miR-208 are dysregulated in human myocardial infarction. Cardiology 115: 163-169. http://dx.doi.org/10.1159/000268088

Chen HH, Chen WP, Yan WL, Huang YC, et al. (2015). NRIP is newly identified as a Z-disc protein, activating calmodulin signaling for skeletal muscle contraction and regeneration. J. Cell Sci. 128: 4196-4209. http://dx.doi.org/10.1242/jcs.174441

Cheng H, Kimura K, Peter AK, Cui L, et al. (2010). Loss of enigma homolog protein results in dilated cardiomyopathy. Circ. Res. 107: 348-356. http://dx.doi.org/10.1161/CIRCRESAHA.110.218735

D’Angelo D, Palmieri D, Mussnich P, Roche M, et al. (2012). Altered microRNA expression profile in human pituitary GH adenomas: down-regulation of miRNA targeting HMGA1, HMGA2, and E2F1. J. Clin. Endocrinol. Metab. 97: E1128-E1138. http://dx.doi.org/10.1210/jc.2011-3482

Flowers E, Froelicher ES and Aouizerat BE (2013). Measurement of MicroRNA: a regulator of gene expression. Biol. Res. Nurs. 15: 167-178. http://dx.doi.org/10.1177/1099800411430380

Genetics and Molecular Research 15 (4): gmr15049313 
Frey N, Richardson JA and Olson EN (2000). Calsarcins, a novel family of sarcomeric calcineurin-binding proteins. Proc. Natl. Acad. Sci. USA 97: 14632-14637. http://dx.doi.org/10.1073/pnas.260501097

Huang YH, Lin KH, Chen HC, Chang ML, et al. (2012). Identification of postoperative prognostic microRNA predictors in hepatocellular carcinoma. PLoS One 7: e37188. http://dx.doi.org/10.1371/journal.pone.0037188

Lai CY, Yu SL, Hsieh MH, Chen CH, et al. (2011). MicroRNA expression aberration as potential peripheral blood biomarkers for schizophrenia. PLoS One 6: e21635. http://dx.doi.org/10.1371/journal.pone.0021635

Lee JS, Kim JM, Lim KS, Hong JS, et al. (2013). Effects of polymorphisms in the porcine microRNA MIR206 / MIR133B cluster on muscle fiber and meat quality traits. Anim. Genet. 44: 101-106. http://dx.doi.org/10.1111/j.13652052.2012.02362.x

Lin X, Ruiz J, Bajraktari I, Ohman R, et al. (2014). Z-disc-associated, alternatively spliced, PDZ motif-containing protein (ZASP) mutations in the actin-binding domain cause disruption of skeletal muscle actin filaments in myofibrillar myopathy. J. Biol. Chem. 289: 13615-13626. http://dx.doi.org/10.1074/jbc.M114.550418

McDaneld TG, Smith TP, Doumit ME, Miles JR, et al. (2009). MicroRNA transcriptome profiles during swine skeletal muscle development. BMC Genomics 10: 77. http://dx.doi.org/10.1186/1471-2164-10-77

Moriscot AS, Baptista IL, Bogomolovas J, Witt C, et al. (2010). MuRF1 is a muscle fiber-type II associated factor and together with MuRF2 regulates type-II fiber trophicity and maintenance. J. Struct. Biol. 170: 344-353. http://dx.doi. org/10.1016/j.jsb.2010.02.001

Siegismund CS, Rohde M, Kühl U, Escher F, et al. (2016). Absent microRNAs in different tissues of patients with acquired cardiomyopathy. Genomics Proteomics Bioinformatics 14: 224-234. http://dx.doi.org/10.1016/j.gpb.2016.04.005

Siengdee P, Trakooljul N, Murani E, Schwerin M, et al. (2013). Transcriptional profiling and miRNA-dependent regulatory network analysis of longissimus dorsi muscle during prenatal and adult stages in two distinct pig breeds. Anim. Genet. 44: 398-407.http://dx.doi.org/10.1111/age.12032

Tabebordbar M, Wang ET and Wagers AJ (2013). Skeletal muscle degenerative diseases and strategies for therapeutic muscle repair. Annu. Rev. Pathol. 8: 441-475. http://dx.doi.org/10.1146/annurev-pathol-011811-132450

Tran T, Andersen R, Sherman SP and Pyle AD (2013). Insights into skeletal muscle development and applications in regenerative medicine. Int. Rev. Cell Mol. Biol. 300: 51-83. http://dx.doi.org/10.1016/B978-0-12-405210-9.00002-3

von Nandelstadh P, Ismail M, Gardin C, Suila H, et al. (2009). A class III PDZ binding motif in the myotilin and FATZ families binds enigma family proteins: a common link for Z-disc myopathies. Mol. Cell. Biol. 29: 822-834. http:// dx.doi.org/10.1128/MCB.01454-08

Wang H, Zhu Z, Wang H, Yang S, et al. (2006). Characterization of different expression patterns of calsarcin-1 and calsarcin-2 in porcine muscle. Gene 374: 104-111. http://dx.doi.org/10.1016/j.gene.2006.01.035

Ying SY, Chang DC and Lin SL (2013). The MicroRNA. Methods Mol. Biol. 936: 1-19. http://dx.doi.org/10.1007/978-162703-083-0 1

Yu X and Zuo Q (2013). MicroRNAs in the regeneration of skeletal muscle. Front. Biosci. (Landmark Ed.) 18: 608-615. http://dx.doi.org/10.2741/4124

Genetics and Molecular Research 15 (4): gmr15049313 